\title{
GÊNERO E A PROFISSÃO DE ENFERMAGEM: MULHERES, SIMBOLOGIAS, CONDUTAS E VESTIMENTAS EM MEADOS DO SÉCULO XX
}

\author{
Felipe Bastos Maranezi ${ }^{1}$ \\ Natália Scarabeli Zancanari ${ }^{2}$
}

\begin{abstract}
RESUMO: As construções epistemológicas acerca da mulher enfermeira e das questões de gênero foram estabelecidas por meio dos seus uniformes, condutas e símbolos presentes em sua profissão e na relação com o universo da moda, onde, buscamos contextualizar fatos comportamentais e culturais em meados do século XX. Nesta perspectiva creiamo-nos que a justificativa deste artigo se dá devido à carência bibliográfica no campo acadêmico que se destine ao entendimento da história da mulher com a sua entrada na profissão de enfermagem e a sua analogia com a moda, sendo que, as vestimentas da mulher enfermeira leva consigo um grande valor simbólico. O uniforme feminino de enfermagem, no contexto historiográfico, demonstra-se componente indispensável para o entendimento de condutas da profissão e também perante as questões de gênero que a permeiam. Diante disso, a pesquisa a ser realizada neste trabalho pode ser classificada como objeto. Isto porque é possível reconhecer as principais características do trabalho a ser realizado. Quanto à metodologia, o trabalho em mãos faz a opção pelo método (dialético). Esta opção se justifica porque o método escolhido permite entender o ser humano como um ser ativo e de relações e que o conhecimento é construído por esse sujeito na sua relação com os outros e com o mundo.
\end{abstract}

Palavras-chave: moda, mulher, enfermeiras, simbologia, condutas.

ABSTRACT: The epistemological constructions about the female nurse and gender issues were established through their uniforms, behaviors and symbols present in their profession and in the relationship with the fashion universe, where we seek to contextualize behavioral and cultural facts in the mid-20th century. In this perspective, we believe that the justification of this article is due to the lack of literature in the academic field that is intended to understand the history of women with their entry into the nursing profession and its analogy with fashion, being that, a nurse woman carries a great symbolic value. The female nursing uniform, in the historiographic context, proves to be an indispensable component for understanding the conduct of the profession and also in view of the gender issues that permeate it. Therefore, the research to be carried out in this work can be classified as an object. This is because it is possible to recognize the main characteristics of the work to be performed. As for the methodology, the work in hand makes the option for the (dialectical)

\footnotetext{
${ }^{1}$ Doutorando em História do Programa de Pós- Graduação em História. Universidade Estadual de Maringá, Maringá/PR,Brasil. E-mail: felipebmaranezi@hotmail.com ORCID: https://orcid.org/0000-0003-1271-3430

2 Doutoranda em História do Programa de Pós- Graduação em História. Universidade Estadual de Maringá, Maringá/PR, Brasil. E-mail: nataliazancanari@yahoo.com.br ORCID: https://orcid.org/0000-0002-4253-2086
} 
method. This option is justified because the chosen method allows to understand the human being as an active being and of relationships and that knowledge is built by this subject in his relationship with others and with the world.

Keywords: fashion, woman, nurses, symbolism, behavior.

RESUMEN: Las construcciones epistemológicas sobre las enfermeras y los problemas de género se establecieron a través de sus uniformes, comportamientos y símbolos presentes en su profesión y en la relación con el universo de la moda, donde buscamos contextualizar los hechos conductuales y culturales a mediados del siglo XX. En esta perspectiva, creemos que la justificación de este artículo se debe a la falta de literatura en el campo académico que pretenda comprender la historia de las mujeres con su ingreso a la profesión de enfermería y su analogía con la moda, siendo que, Una mujer enfermera tiene un gran valor simbólico. El uniforme femenino de enfermería, en el contexto historiográfico, demuestra ser un componente indispensable para comprender la conducta de la profesión y también en vista de los problemas de género que la impregnan. Por lo tanto, la investigación a realizar en este trabajo puede clasificarse como un objeto. Esto se debe a que es posible reconocer las características principales del trabajo a realizar. En cuanto a la metodología, el trabajo en mano hace la opción para el método (dialéctico). Esta opción está justificada porque el método elegido permite entender al ser humano como un ser activo y de relaciones y ese conocimiento se construye por este sujeto en su relación con los demás y con el mundo.

Palabras clave: moda, mujer, enfermeras, simbolismo, comportamiento.

Por muito tempo, as mulheres eram menos vistas no espaço público, elas atuavam em família, confinadas em casa, invisíveis. Em muitas sociedades, a invisibilidade e o silêncio das mulheres faziam e ainda fazem parte da ordem das coisas. É a garantia de uma cidade tranquila. Sua aparição em grupo sempre causou medo. Entre os gregos, é a desordem. Sua fala em público é indecente. Até mesmo o corpo das mulheres amedronta. É preferível que esteja coberto por véus. Os homens são indivíduos, pessoas, trazem sobrenomes que são transmitidos. Alguns são "grandes", "grandes homens". As mulheres não têm sobrenome, têm apenas um nome. Aparecem sem nitidez, na penumbra dos grupos obscuros. "As mulheres e as crianças", "primeiro", ou ao lado, ou para fora, dependendo do caso, no ensaio Tristes tropiques, Claude Lévi-Strauss descreve uma aldeia depois da partida dos homens para caçar: não havia mais ninguém, diz ele, exceto as mulheres e as crianças (PERROT, 2019).

Porque as mulheres não pertenceriam à história? Para a historiadora Michelle Perrot (2019), tudo depende do sentido que se dê à palavra "história". A história é o que acontece, a sequência dos fatos, das mudanças, das revoluções, das acumulações que tecem o devir das sociedades. As mulheres ficaram muito tempo destinadas à obscuridade de uma inenarrável reprodução, estivessem fora do tempo, ou pelo menos, fora do acontecimento. Confinadas no silêncio de suas narrativas, se não bastasse, sofrem de inúmeras violências, tanto verbais quanto físicas, chegando ao extremo de uma fatídica morte. 
Compreendemos que tanto os homens quanto as mulheres sofrem os reflexos da sociedade desigual em que estão inseridos, não se trata apenas de classes sociais, porque independe de posição social, a desigualdade de gênero alcança as diversas classes sociais. A construção histórica da ideia que o homem é o gênero dominante, que insere a mulher em patamar inferior não foi construída apenas por homens, mas também por mulheres que viveram e cresceram com essa realidade, e tomaram para si a posição de sexo frágil, talvez por falta de oportunidade, ou até mesmo por proteção, o fato é que essa realidade levou séculos para ser construída, e pode levar muito tempo para ser desconstruída (SILVA; ALBERTON, 2019).

Scott (1989), em seus ensaios trata da relação entre homens e mulheres a partir de uma ótica em que estes sujeitos não sejam vistos de forma separada. Para a historiadora, o caminho que se estava seguindo, o de alguns pesquisadores mostrarem novas informações sobre as mulheres no passado, não estava modificando a importância atribuída às atividades femininas, pelo contrário, estava sendo colocadas em separado, dando a elas um lugar marginalizado em relação aos temas masculinos dominantes e universais.

Diante da necessidade e a urgência de discutir e analisar de modo mais rigoroso o processo de como se dá e porque se reproduz a invisibilidade da mulher no processo de produção do conhecimento histórico, Scott (1989) explica como que surge o conceito de "Gênero". A autora enfatiza os significados variáveis e contraditórios atribuídos à diferença sexual, os processos políticos através dos quais esses significados são construídos, a instabilidade e maleabilidade das categorias "mulheres" e "homens", e os modos pelos quais essas categorias se articulam em termos da outra, embora de maneira não consistente ou da mesma maneira em cada momento.

O gênero se torna, aliás, uma maneira de indicar as "construções sociais" - a criação inteiramente social das ideias sobre os papeis próprios aos homens e às mulheres. É uma maneira de se referir às origens exclusivamente sociais das identidades subjetivas dos homens e das mulheres. O gênero é, segundo essa definição, uma categoria social imposta sobre um corpo sexuado. (SCOTT, 1989, p.7).

Segundo Scott (1989), o estudo do gênero coloca em debate questões que vão muito além do sexo e da sexualidade, Carla Bassanezi alega sobre como os conceitos de feminino e masculino eram entendidos como inerentes à natureza do homem e da mulher nos anos de 1950, data que marca o auge do transporte aéreo no que diz respeito ao seu status de glamour e requinte típicos dos "anos dourados". Enquanto a mulher era definida por características como pureza, a docilidade, a delicadeza, fragilidade, resignação e maternidade; o homem era 
reconhecido por sua força, autoridade ousadia e poder. Para a mentalidade da época essas eram características tidas como naturais e determinavam quais os espaços onde homens e mulheres deveriam atuar.

As ideias construídas de masculinidade e feminilidade não são fixas, tendo em vista suas variações de acordo com o contexto em que estão inseridas. Logo, haverá um conflito entre a necessidade do sujeito de uma aparência de completude e a imprecisão da nomenclatura, a relatividade da sua significação e sua dependência em relação à repressão. “Essas interpretações tornam problemáticas as categorias 'homem' e 'mulher', sugerindo que a construção do masculino e do feminino é algo subjetivo e não uma característica inseparável" (SCOTT, 1989).

Para Finco (2015), homens e mulheres adultos educam crianças definindo em seus corpos diferenças de gênero. As características físicas e os comportamentos esperados para meninos e meninas são reforçados, às vezes inconscientemente, nos pequenos gestos e práticas do dia-a-dia na educação infantil. Por exemplo, a forma como a família ou a professora conversa com a menina, elogiando sua meiguice ou como justifica a atividade sem capricho do menino. O fato de pedir para uma menina a tarefa de ajudar na limpeza e ao menino para carregar algo já demonstra como as expectativas são diferenciadas. O que é valorizado para a menina não é, muitas vezes, apreciado para o menino, e vice-versa.

O minucioso processo de feminilização e masculinização dos corpos, presente no controle dos sentimentos, no movimento corporal, no desenvolvimento das habilidades e dos modelos cognitivos de meninos e meninas está relacionado à̀ força das expectativas que nossa sociedade e nossa cultura carregam. Esse processo reflete-se nos tipos de brinquedos que lhes são permitidos e disponibilizados: para que as crianças "aprendam", de maneira muito prazerosa e mascarada, a comportar-se como "verdadeiros" meninos e meninas (FINCO, 2015).

A diferenciação com base no gênero aparece em evidência quando falamos especificamente dos brinquedos das crianças. Para as meninas existe uma vasta gama de objetos miniaturizados que imitam os utensílios caseiros de cozinha, quartinhos para bebês, ferros de passar, serviços de chá, eletrodomésticos, carrinhos, banheirinhas e bonecas com o respectivo enxoval. Para os meninos em geral os brinquedos divergem completamente: carrinhos, caminhões, motos, aviões, arminhas, bolas, skates. A escolha de uma profissão na vida adulta se torna algo pré-estabelecido "inconscientemente" nas brincadeiras e brinquedos ofertados para meninos e meninas, onde ocupam um lugar importante no processo de construção das identidades desses futuros adultos, onde meninas são orientadas a serem; 
donas de casa, enfermeiras, secretárias, e os meninos a seguirem profissões tais como; engenheiro, médico, advogado, piloto de aviões (FINCO, 2015).

$\mathrm{Na}$ cultura patriarcal vigente, existe uma subdivisão limitada entre masculino/feminino e homem/mulher, visto que cada um possui regras para seu modo de comportamento social característico, excluindo, então, a possibilidade de não binariedade, ou fluidez. A moda é um dos fatores principais para a identificação e afirmação do indivíduo com seu gênero, tendo em vista que por meio dela é dada a devida significância ao corpo vestido, alegando seu papel dentro de um grupo (DIAS; PIETROBELLI, 2018).

O corpo humano é considerado objeto da moda; logo, o sistema de moda se torna elemento de representação, tornando possível a afirmação e a significância do gênero no contexto social. Apropriando-se dos conceitos de representação de Chartier (1991), que afirma a negatividade da existência de prática ou estrutura que não seja produzida pelas representações, pode-se afirmar que as práticas de se vestir são atos de apropriação e de circulação das representações de moda. E é através da representação que o indivíduo legitima a sua existência, afirmando sua identidade.

A moda é um fenômeno que apresenta possibilidades de diferenciação ou unidade, assumindo caráter distintivo quando relacionada a papéis sociais e de representação quando apresentada como símbolo. Assim, pode-se afirmar que ela é um elemento crucial na representação social e afirmação do gênero. Já o gênero é uma instituição simbólica, erroneamente associado a normas biológicas. Levando em conta a premissa do gênero como construção social, e não como um atributo fisiológico, alguns objetos são necessários para sua significação e legitimação no meio social, incluindo o vestuário (DIAS; PIETROBELLI, 2018).

Segundo Bassanezi (2006) o próprio vestuário de meados do século XX servia para acentuar as diferenças entre os sexos feminino e masculino. As mulheres usavam saias amplas que, como em outras épocas, serviam para demarcar o distanciamento em relação aos homens, as cinturas bem marcadas e saltos altos que objetivavam demonstrar a fragilidade e a delicadeza do ser humano feminina.

Ser mãe, esposa e dona de casa era considerado o destino natural das mulheres. Na ideologia dos Anos Dourados, maternidade, casamento e dedicação ao lar faziam parte da essência feminina; sem história, sem possibilidade de contestação (BASSANEZI, 2006, p.609).

Essa vocação prioritária era a marca da feminilidade de meados do século XX e estava impregnada no processo de educação das mulheres. Como diz a autora Bassanezi (2006), os 
conselhos sobre como se comportar estavam sempre presentes nas conversas entre mãe e filha, nos romances para moças, nos sermões do padre, nas opiniões de um juiz ou legislador sintonizado com seu tempo.

Da mesma forma que o Brasil adotou, com algumas ressalvas, as tendências internacionais de modernização e liberação feminina, que foram impulsionadas no pós-guerra e pelo desenvolvimento econômico que incorporou a mão-de-obra feminina, a profissão de enfermeira estava entre as atividades que se firmaram entre as mulheres.

\section{A mulher enfermeira: moda, moral e a simbologia da profissão}

A mulher enfermeira e a sua evolução como profissão teve seu início quando na França, no fim do século XIX, o doutor Bourneville - um radical - promove a laicização dos hospitais parisienses. Ele opta pelo modelo das serventes, pouco qualificadas, auxiliares dos médicos. Mal pagas, jovens solteiras, são obrigadas a ficar em alojamentos do hospital sob vigilância. $\mathrm{O}$ modelo da irmã religiosa pesa sobre elas. Muitas jovens bretãs se empregaram, preferindo o serviço no hospital a trabalhar em casas de família. Posteriormente desenvolveuse um ensino de enfermagem em escolas particulares, sob a iniciativa de protestantes que se inspiraram em Florence Nightingale. Assim se estabeleceu a escola de enfermagem de Bourdeaux. Era preciso promover uma formação e obter diplomas, necessários a uma qualificação reconhecida e a melhores salários; passar do serviço doméstico a uma verdadeira profissão, aliando conhecimento médicos e saberes sobre o corpo (PERROT, 2019).

Segundo Matos e Borelli (2018), para que possamos entender a entrada da mulher na profissão de enfermeira e a sua relação com a moda e gênero, é necessário compreender o momento histórico que a mulher e sua relação com o trabalho estavam passando. Entre 1920 e 1940, ocorreu uma diminuição da presença feminina no universo fabril, devido a uma conjunção de fatores: as transformações no processo de industrialização (desenvolvimento de setores tradicionalmente masculinos como o metalúrgico, o siderúrgico e o mecânico e adoção de novos métodos de organização do trabalho) somadas às ações (públicas, médicas, e do movimento operário) contra o trabalho feminino e à legislação dita protetora deste. Entretanto, apesar da tendência de diminuição da presença relativa no trabalho fabril, as mulheres se mantiveram no mercado de trabalho.

Concomitantemente com o refluxo da participação feminina no setor industrial, as mulheres passaram a ocupar mais espaço em empregos menos visíveis e estáveis, 
particularmente no serviço doméstico e no trabalho no domicílio. Também começaram a exercer novas funções no comércio e na burocracia dos escritórios, em aéreas para as quais as mulheres eram consideradas "mais aptas" - como Magistério, Enfermagem, Farmácia e Odontologia -, os obstáculos foram menores, mas ainda significativos (MATOS, BORELLI, 2018).

Em decorrência da forte relação da enfermagem com os princípios religiosos, a ocupação das enfermeiras sempre foi comparada ao papel desempenhado por entidades celestiais (anjos, querubins). Assim como anjos, delega-se à enfermeira o papel de zelar, de guardar e de proteger. Para isso, ela precisa estar sempre pronta para servir, embalada por um ideal solidário, fraterno e devotado (PASSOS, 2012).

Atitude que, assim como acontece com os anjos, tem sido vista como intermediária entre Deus e "seus filhos", entre o médico e o paciente, entre a instituição e o cliente, e pode ser verificada através da postura servil, abnegada e fraterna das enfermeiras para com as pessoas a quem cuidam, assim como na atitude submissa e de acatamento que têm tido diante dos superiores hierárquicos, quase sempre, do sexo masculino. Essas atitudes podem ser percebidas durante a maior parte de sua história que é contata pelos seus atos e pela moda que é facilmente atribuída ao uso de seus uniformes (PASSOS, 2012).

Segundo Almeida Peres e Alencar Barreira (2003), o uniforme é um tipo específico de vestimenta para determinada categoria de indivíduos e identifica-os como pertencentes a um grupo ou a uma instituição. Caracterizando a figura de quem o está usando, o uniforme funciona como objeto disciplinador, uma vez que padroniza as atitudes e comportamentos de quem o veste, seja ele uniforme militar, religioso, escolar ou, como no caso em estudo, profissional.

Vestir um uniforme, determinado por autoridades externas, significa estar apropriadamente vestido para pertencer a um determinado grupo, significa envolvimento com ele e conformação com seus padrões sociais. Não se identifica um indivíduo uniformizado pelo seu nome, e sim pela instituição à qual representa. $\mathrm{O}$ uniforme tem valor simbólico e significado moral, colocando quem o veste sob censura, uma vez que as consequências de suas atitudes, para bem ou mal, recairão sobre o grupo a que pertence, e tornando-se, portanto, objeto inclusive de sanções disciplinadoras. Desvantagens físicas e psicológicas podem ser ocultadas pelo uniforme, concedendo a quem o usa dignidade e confiança. Vestir um uniforme pode facilitar a transição de um papel para outro (ALMEIDA PERES, ALENCAR BARREIRA, 2003). 
Os uniformes femininos se revestem de características especiais, primeiro porque o vestuário feminino é mais variado, em peças e em acessórios, do que o masculino, e depois porque sua relação com a moda é mais estreita do que os uniformes masculinos (LURIE, 1997. p.33-34).

A história da indumentária da enfermeira, segundo Simili (2010), sofreu as influências das roupas militares. Nos anos de 1940, sobre o vestido que tinha mangas compridas e gola fechada, as enfermeiras usavam um sobretudo (ou capa), com abotoaduras na parte do busto, deixando aberta uma parte que dava a ver o vestido. "Esta capa era de tom azul escuro, cor predominante dos uniformes militares". Vale destacar que essas capas eram usadas pelas enfermeiras para circularem pelas ruas entre idas e vindas dos locais de trabalho e serviram de influência para compor os uniformes das primeiras comissárias de bordo da aviação.

Para os anos 1950, algumas permanências são identificadas no vestuário da enfermeira. Sob os vestidos, que eram com corte "godê", as "anáguas" serviam para dar volume à roupa, deixando-as meio rodadas. A cintura era marcada por cintos ou faixas que modelavam o corpo (SIMILI, 2010).

O período denominado "era de ouro" ou "anos dourados" é historicamente reconhecido pela recuperação dos países europeus e do Japão da Segunda Guerra Mundial, segundo Hobsbawm (1995) e nos primeiros anos depois de 1945 os países mediram seu sucesso tomando como base o quanto se haviam aproximado de um objetivo estabelecido em referência ao passado, não ao futuro. Nos Estados não comunistas, a recuperação também significava deixar para trás o medo de revolução social e avanço comunista, herança da guerra e da Resistência. Enquanto a maioria dos países (além de Alemanha e Japão) voltava a seus níveis pré-guerra em 1950, o início da Guerra Fria e a persistência de poderosos partidos comunistas na França e Itália desencorajavam a euforia. De qualquer modo, os benefícios materiais do crescimento levaram algum tempo para se fazer sentir.

A revolução tecnológica neste período pós-guerra começou a mover um impressionante surto econômico. Nessa medida, multiplicaram-se não apenas produtos melhorados de um tipo preexistente, mas outros inteiramente sem precedentes, incluindo muitos quase inimagináveis antes da guerra. Alguns produtos revolucionários, como os materiais sintéticos conhecidos como "plásticos", haviam sido desenvolvidos no período entre guerras, ou até começado a entrar em produção comercial, como o náilon (1935), poliestireno e politeno. Outros, como a televisão e a gravação em fita magnética, mal se achavam no estágio experimental. A guerra, com suas demandas de alta tecnologia, preparou vários processos revolucionários para posterior uso civil, embora um pouco mais do lado britânico 
(depois assumido pelos EUA) que entre os alemães com seu espírito científico: radar, motor a jato e várias ideias e técnicas que prepararam o terreno para a eletrônica e a tecnologia de informação do pós-guerra (HOBSBAWM, 1995).

O Brasil também ingressa numa fase de desenvolvimento acelerado, do ponto de vista econômico nos anos de 1950. A urbanização e a industrialização avançam com vigor. A produção industrial diversifica-se. Inúmeras transformações ocorrem na infraestrutura e no cotidiano das cidades (principalmente no estado de São Paulo). Os grandes centros atraem um enorme número de imigrantes, aumentando as diferenças regionais, a região sudeste é a que mais irá receber tais pessoas. (PINSKY, 2014).

Para Pinsky (2014) as transformações no período pós segunda guerra tem reflexos importantes no status socioeconômico das mulheres. Por um lado, o incremento do setor secundário e as mudanças na produção eliminam várias ocupações artesanais ou domésticas, expulsando um número significativo de mulheres do mercado de trabalho, contudo, surgem para elas novas oportunidades em consequência do aumento de empregos no setor terciário. Cresce também nessa época a demanda por trabalhos considerados femininos, como secretária, professora e enfermeira. Como observou o sociólogo Emílio Willems em 1954, apesar do fato de que as mulheres podem, agora, escolher, entre várias possibilidades profissionais, ainda há poucas mulheres, no Brasil que seguem alguma carreira. Conforme afirma Pinsky (2014), para a maioria esmagadora das mulheres, o casamento está em primeiro plano e nem estudos nem profissão fazem com que ele seja adiado ou rejeitado. Ao longo dos Anos Dourados, é comum ouvir que carreira e matrimônio são inconciliáveis. As mulheres encontram muitas barreiras ao tentar prosseguir com os estudos universitários ou investir em uma profissão.

O sentido da palavra enfermagem, segundo Passos (2012), está originalmente conexo com o de mulher à medida que ele surgiu para designar os cuidados maternos com a criança. Cuidados que se davam, de maneira geral, em três direções: "no nutrir, no direcionar e no manter”. O nutrir não estava colocado apenas no plano físico de alimentar o corpo, mas principalmente como uma forma de "proteger, fortalecer, manter e aliviar". O que indica uma postura solidária e afetuosa. Direcionar, por sua vez, além do sentido comum de indicar um "norte", mostrar um caminho, pode ser tomado também como uma maneira de auxiliar o indivíduo a se integrar socialmente. Por último, o manter, que assim como o direcionar, privilegia o sentido da integração social e garante a unidade e a harmonia do indivíduo na sociedade. 
Para Matos e Borelli (2018), a profissão de enfermagem no Brasil, até o início do século $\mathrm{XX}$, as enfermarias dos hospitais eram lugares sombrios e sujos, desconfortáveis e insalubres, recebendo, no mesmo espaço, pobres, mendigos e doentes de todos os tipos. A posterior difusão dos preceitos higienistas foi transformadora: passou-se a ressaltar a necessidade de ordem, limpeza e higiene. Com as novas práticas médicas que surgiam e a concentração das intervenções nos espaços hospitalares, ampliaram-se as possibilidades de cura e a especialização de áreas médicas.

Identificar a enfermeira com anjo é uma forma de reafirmar uma identidade segundo menciona Passos (2012), e ao ponto que, ao se distanciar do profissionalismo e de uma postura de engajamento político, ela é conservada como um ser que exerce uma ocupação sagrada. Por outro lado, ver a enfermagem como sagrada serve também para afastá-la do aspecto profissional, pois a apresenta como uma atividade que lida com o ser humano, quase sempre diante do sofrimento, da dor e da morte, e que para enfrentar tais problemas, a profissional precisa, antes de tudo, de uma boa dose de fé, de solidariedade, abnegação e disciplina, muito mais do que competência técnica, política e postura crítica frente à profissão e ao mundo.

Em meados do século XX, na busca por melhorar a qualidade dos serviços prestados, a enfermagem acabou saindo da órbita do controle das freiras e passou a responder diretamente à chefia dos médicos. Nessa época, a "boa enfermeira" era valorizada por habilidades como esmero, paciência, abnegação, cautela e docilidade no trato geral do paciente (limpar, arrumar, ministrar remédios e curativos), contribuindo para o bom êxito das prescrições médicas (MATOS, BORELLI, 2018).

Segundo Matos e Borelli (2018), no início, a formação em enfermagem era adquirida na prática hospitalar, mas, já na virada do século XIX para o XX, iniciativas públicas e particulares promoveram a criação de cursos específicos, alguns de duração efêmera. A estruturação da enfermagem profissional no Brasil ocorreu na década de 1920, conjugando iniciativas do Estado e da Fundação Rockeffeler com a criação da Escola Anna Nery no estado da Bahia. Nas décadas seguintes, escolas de enfermagem foram instaladas em vários pontos do país (Rio de Janeiro, São Paulo, Belo Horizonte, Salvador, Rio Grande do Sul e Ribeirão Preto).

Para Almeida Peres e Alencar Barreira (2003), ainda no cenário brasileiro, desde a sua criação, a Escola Anna Nery determinou um padrão de qualidade, de maneira que a assistência prestada por suas alunas e diplomadas, bem como seu comportamento, foram sempre admirados e reconhecidos no meio profissional e na sociedade em geral. 
A disciplina das enfermeiras é outra qualidade destacada por Passos (2012), que compõe o perfil dos "anjos" alunas da Escola Anna Nery da Bahia, não como uma invenção dessa prática educativa, e sim como uma tradição que acompanha a enfermagem desde os seus primórdios. No concernente à Escola de Enfermagem, ela podia ser sentida em todas as instâncias: desde a exigência do cumprimento dos horários de aulas, de estágios, de saídas e chegadas, na forma de cuidar os cabelos e as unhas, o perfume permitido, e especialmente o uniforme que caracterizava exatamente essa conduta exemplar, simbolizando virtudes espirituais, morais e profissionais como: humildade, competência, abnegação e altruísmo.

A cerimônia de entrega de toucas era um momento muito aguardado pelas alunas da Escola Anna Nery, pois sabiam que o momento em que a touca, o broche, o avental branco, a capa e a braçadeira, passavam a fazer parte de seu uniforme, com estes, lhes seriam cobradas atitudes dignas e competentes de suas instrutoras (ALMEIDA PERES, ALENCAR BARREIRA, 2003).

A utilização do uniforme de enfermeira, significava não só estar usando a roupa determinada pela escola de enfermagem, mas estar também com os cabelos penteados e presos em rede, sem maquiagem, com unhas curtas, limpas e sem esmalte, sem joias ou adornos, usando apenas um relógio de ponteiros de segundos, peça que acompanhava o uniforme. Uma vez que "o vocabulário das roupas não inclui apenas peças de roupas, mas também estilos de cabelos, acessórios, joias, maquiagem e decoração do corpo" (LURIE, 1997. p.20).

Ao tratar dos cabelos femininos, penteados e cortes, para Perrot (2019), os cabelos são a mulher, a carne, a feminilidade, a tentação, a sedução, o pecado. Há uma erotização dos cabelos das mulheres, principalmente o século XIX, grande século do esconder/mostrar, que fortalece o erotismo. Isso se estende do erotismo refinado dos pintores, em particular dos pintores vienenses (Klimt, Schiele...), ao erotismo mais vulgar dos cartões postais de 1900 que retratam o nu e os cabelos, ainda mais quando representam as mulheres das colônias ou as judias.

Cobrir ou enfeitar os cabelos, por conseguinte, é objeto de convenções, de distinção e de moda. O penteado transforma os cabelos em peça do vestuário, em objeto de arte e de moda. Passam a fazer parte da mise-en-scène da sedução, da elegância. Segundo Perrot (2019), no início do século XX, em relação aos cortes de cabelo e penteados femininos, a guerra acelera o movimento. Para as comodidades do trabalho, enfermeiras, motoristas de ambulância, condutoras de bonde, operárias das fábricas de munição, presentes em tantos cartões postais, se modernizam. 


\section{Considerações Finais}

Ao longo da história, a moda definiu padrões estéticos e de beleza baseados no padrão binário de gênero (feminino e masculino). A roupa revela atributos e características da pessoa que a está usando, assim como o tempo em que ela está inserida. As roupas têm uma linguagem própria e comunicam sobre o sexo, a idade e a classe social de quem as veste, podendo ainda dar informações importantes em relação ao trabalho, origem, personalidade, gostos e humor da pessoa naquele momento (LURIE, 1997 p.19). A moda, ou seja, as mudanças periódicas que ocorrem nos estilos de vestuários estão associadas às variações das tendências políticas, sociais e culturais representando, em certa medida, as formas de pensar dos grupos e dos indivíduos, bem como os costumes de cada época (LURIE, 1997. p.74).

O acesso a espaços públicos era simbolizado através dos uniformes, para mulheres/enfermeiras, que acreditavam que tal indumentária era um emblema de mudanças que instrumentalizava novos modos de ser, agir e pensar. Segundo Simili (2008), ele favorece a incorporação de novos valores e expectativas que recaem sobre as mulheres (autocontrole, segurança, disciplina, obediência, confiança, organização, respeito à ordem e à hierarquia), o que ampliava a autoconfiança quanto ao potencial profissional das mulheres e favorecia sua emancipação. Usar o uniforme implicava compreender, aceitar e obedecer às regras e atender as expectativas sociais em torno da atuação das mulheres em prol da nação.

Os uniformes utilizados por alunas e enfermeiras foram de grande importância para a diferenciação das diversas categorias de exercentes, para a formação de uma identidade grupal e para a valorização da profisssão na sociedade em meados do século XX. As modificações por eles sofridas se relacionam com as variações da moda feminina daquele período e/ou por determinados problemas em sua praticidade (DE ALMEIDA PERES, ALENCAR BARREIRA, 2003).

As enfermeiras, à medida que foram conquistando espaço profissional e construindo uma nova visão da enfermagem, passaram a questionar o significado de seus uniformes, que sofreram transformações significativas até se tornarem únicos para alunas, professoras e enfermeiras. O uso da touca, principal objeto de caracterização e veneração da enfermeira, tornou-se polêmico até começar a cair em desuso, a partir da década de 60 , quando as enfermeiras passaram a ser mais uma pessoa de branco dentro do ambiente hospitalar junto com os demais profissionais da equipe da saúde. Os uniformes utilizados por alunas e enfermeiras foram de grande importância para a diferenciação das diversas categorias de 
exercentes, para a formação de uma identidade grupal e para a valorização da profissão na sociedade. As modificações por eles sofridas se relacionam com as variações da moda feminina da época, ou foram determinadas por problemas de ordem prática, relacionados à aquisição dos artigos ou sua confecção (ALMEIDA PERES, ALENCAR BARREIRA, 2003).

Para Passos (2012), diante das alterações sofridas em decorrência das transformações histórico-sociais, o uniforme utilizado pelas enfermeiras continuou articulado com princípios morais que servem para disfarçar o corpo e tudo aquilo que possa despertar nas profissionais e nos assistidos pensamentos e atos voltados para a sensualidade e sexualidade.

Os artefatos têm vida, alma e memória segundo relata Appadurai (1986), o uniforme tem o poder de trazer consigo a história de vida da pessoa, o que nos leva a confirmar o quanto as roupas comporta um rico potencial de análise, por serem objetos centrais a experiência humana, revestirem o corpo, acompanharem a trajetória profissional, e participarem de momentos tristes e felizes, de tensão e emoção, isso torna o uniforme muito significativo, atuando como uma espécie de "segundo pele" para aquela pessoa que o veste por tantas horas, dias, ou até mesmo ao longo de uma vida.

Por fim, podemos entender de forma explícita, a relação da moda com a profissão de enfermagem e o papel da mulher neste contexto, sendo que, a moda permite que se interprete as pessoas pelo traje que usam; sendo assim uma pessoa mal vestida, provavelmente, será vista com desconfiança pela sociedade. Dessa forma, o uniforme das enfermeiras evidencia suas qualidades, seus costumes e condutas, sendo assim, tem o poder de construir sua imagem perante a profissão e perante toda a sociedade.

\section{Referências bibliográficas}

ALMEIDA PERES, Maria Angélica; DE ALENCAR BARREIRA, Ieda. Significado dos uniformes de enfermeira nos primórdios da enfermagem moderna. Escola Anna Nery Revista de Enfermagem, v.7, n.1, p. 25-38, 2003.

APPADURAI, Arjun (Org.). The social life of things: commodities in cultural perspective. New York: Cambridge University Press, 1986.

BASSANEZI, Carla. Mulheres dos anos dourados. PRIORI, Mary Del (org.). História das mulheres no Brasil. 8a Ed. São Paulo: Contexto, 2006.

CHARTIER, Roger. O mundo como representação. Estudos Avançados, São Paulo, v. 5, n. 11, p. 173-191, jan./abr. 1991.

DE LUCA, Tania Regina. Mulher em revista. In: PINSKY, Carla Bassanezi (org.); PEDRO, Joana Maria (org.). Nova história das mulheres no Brasil. São Paulo: Contexto, 2018.

DIAS, C. C.; PIETROBELLI, C. S., Reflexões sobre moda e gênero: Uma teoria da reapropriação e resistência. In: XIV Colóquio de Moda - XI edição Internacional - XIII Fórum das Escolas Dorotéia Baduy Pires - V Congresso Brasileiro de Iniciação Científica em Design e Moda. 2018, Curitiba/PR. 
FARIAS, Rita de Cássia Pereira. Entre a igualdade e a distinção: a trama social de uma grande empresa corporificada no uniforme de trabalho. 2010. Tese de Doutorado. Tese de doutorado em antropologia social. Campinas-Unicamp.

FINCO, Daniela. Questões de gênero na educação da pequena infância brasileira. Studi sulla Formazione/Open Journal of Education, v. 18, n. 1, p. 47-57, 2015.

HOBSBAWM, Eric. Era dos extremos: o breve século XX. Editora Companhia das Letras, 1995.

LURIE, Alison. A linguagem das roupas. Rio de Janeiro: Rocco, 1997.

MATOS, Maria Izilda, BORELLI, Andrea. Espaço feminino no mercado de trabalho. In: PINSKY, Carla Bassanezi (org.); PEDRO, Joana Maria (org.). Nova história das mulheres no Brasil. São Paulo: Contexto, 2018.

MOREIRA, R. O avião e o passageiro. In: Pereira MC, Ribeiro S. (orgs.). Os voos da psicologia no Brasil: estudos e práticas na aviação. Rio de Janeiro: Departamento de Aviação Civil - DAC; 2001

PASSOS, Elizete. De anjos a mulheres: ideologias e valores na formação de enfermeiras. SciELO-EDUFBA, 2012.

PERROT, Michelle. Minha história das mulheres. Trad. Ângela M. S. Côrrea. São Paulo: Contexto, 2019.

PINSKY, Carla Bassanezi. Mulheres dos anos dourados. São Paulo: Contexto, 2014.

SCOTT, Joan. Gênero: uma categoria útil de análise histórica. Educação e realidade, UFRGS, v. 20, nº 2, 1995.

SILVA, Maria Isabele; ALBERTON, Mario Henrique. A lei do feminicídio 13.104/2015 e seus impactos no Estado do Paraná. Revista de Estudos Jurídicos, v. 2, n. 29, 2019.

SIMILI, Ivana Guilherme. Educação e produção de moda na segunda guerra mundial. Cadernos Pagu, 31, 2008.

CAMACHO, Priscila; PONTE, Pollyanna. Educação e Moda: Uniformes de Enfermagem na Segunda Guerra Mundial. Moda Palavra e-periódico, v. 3, n. 6, 2010. 